\title{
The Legal Framework for Academic Professional Development for Radiographers in Higher Education
}

\author{
LJUBICA ŽUNIĆ
}

\begin{abstract}
Technology has changed the world of radiography, setting the request for development and promotion of radiography occupation. This article focuses on key factors of education for radiologic technologist / radiographer. The important role of EFRS in promoting and developing advanced educational standards and qualifications for radiographers is elaborated. Harmonization and development of radiographer's profession following technological development considers cooperation among educational institutions, employers and professional bodies, within the framework of European and national legislation. Society should provide the conditions for further education. Obtaining a master's and / or doctoral degree, and integration in teaching and research activities, helps transform radiographers into leadership roles within their departments.
\end{abstract}

Keywords: • Radiologic Technologist / Radiographer - Learning Outcomes • Standard of Qualification • Education •

CoRRESPONDENCE AdDRESS: Ljubica Žunić, University of Split, Univeristy Department of Health Studies, Ruđera Boškovića 35, 21000 Split, Croatia, e-mail: ljubica-zunic@ozs.unist.st. 


\section{Introduction}

The aim of this article is a comparative review of the documents that describe the standards and legal framework for education of radiologic technologist / radiographer ${ }^{1}$, in order to meet the severely developing needs of this profession. Even though the educational institutions in Europe offer varying education programmes at bachelor, master and doctoral level of studies, it was found that the number of radiographers who search for further education remains low.

In just a decade, technology has not only changed the world of radiography, but has also affected the personal lives of radiographers. Almost all the resources that radiography leverage on a daily basis are shifting toward and new technology is rapidly changing the way they perform their daily tasks. Technology is rebuilding every profession today, setting the request for development and promotion of existing professions as well as creating the new ones.

Radiographers are health professionals who operate advanced equipment and must constantly adapt to fast-moving technological skills through, for example, continual professional development, life-long learning processes, workshops, etc. They bear the responsibility for the procedures they perform.

EFRS plays an important role in promoting and developing advanced educational standards, benchmarking and qualifications at both the bachelor and master level of education in radiography, bridging the gap between the education and market demands.

Significant progress for radiographers was made in November 2017, when ESCO ${ }^{2}$ (European Skills, Competences, Qualifications and Occupations), confirmed the upgrade of the Radiographer profession by linking it to the ISCO-08 Major Group 2 "Professionals" instead of ISCO Major Group 3 "Technicians and Associate Professionals".

Therefore, radiographers should be provided by theoretical and practical training for this occupations for which a higher qualification are required. In Croatia, as well as in other Member States of the EU, healthcare professions are regulated by law. This applies to radiologic technologists / radiographers as well, who must satisfy the minimum educational conditions as provided in Directive 2005/36/EC.

Thus, the next decade is likely to witness an increasing number of consultant radiographers who will have to learn about technological advancements in the field, while at the same time taking care to employ limited resources in a cost effective

\footnotetext{
${ }^{1}$ Because of the variety of national and international titles for this profession, the EFRS recommends using the title "Radiographer" in publications. More details, including the List of national titles for radiographers in EFRS member countries, are available from: https://www.efrs.eu/publications/see/2011_EFRS_Definition_of_a_Radiographer?file=298

2 The European multilingual classification of Skills, Competences, Qualifications and Occupations, available from: https:/ec.europa.eu/esco/portal/howtouse/21da6a9a-02d1-4533-8057-dea0a824a17a
} 
manner. Employers have the responsibility for investment in the skills and development of the people they employ. A failure to do so in the long term could negatively impact patient care if the employees are not adequately trained in the latest techniques and technologies (Consultant Radiographers Education, 2013). ${ }^{3}$

\section{The History of Educational Process for Radiologic Technologists / Radiographers in Croatia}

The first educational program for radiographers in Croatia started in the first half of the $20^{\text {th }}$ century and included courses for $\mathrm{X}$-rays. However, the first formal, systematic education for x-ray technicians was established in 1947, on the premises of what is today the Hospital "Sisters of Charity" in Zagreb. Due to the need for a higher level of education for this profession the first college for x-ray technicians was opened in 1956.

The Advanced School of Nursing and Health Technicians was established in 1966 (later School of Health Studies, and today University of Applied Health Sciences in Zagreb) and offered a two year study programme for senior radiologic technologists. In the period from 1966 to 1996 the study programme for senior radiologic technologists (from 1986 the study for radiological medical engineers) remained constant with few changes in the curriculum. Occasionally, dislocated departments of College for nurses in Zagreb for education of radiologic technologists were opened in other regional centers in Osijek, Rijeka and Split (University of Split, School of Medicine, 2010). From that period on, the education was performed at the schools for medicine in Zagreb, Split and Rijeka, and again, the curricula remained largely static, with only small modifications. In 1999 the two year program was extended to three years. A significant step was made in 2005 by accepting the Bologna Declaration (University of Split, School of Medicine, 2010).

Formal training in radiography initially started as vocational education, but then evolved towards more formal higher education, namely undergraduate and graduate university study programmes.

Until 2011, due either to insufficiently developed or unavailable formal higher education, health profession workers improved their competencies only through informal methods of education, or went abroad in order to acquire additional knowledge, skills and formal education.

In order to implement a framework of vertical education within the university education and due to the need for increased staffing in this profession, in 2011, the University Department of Health Studies, University of Split launched its master programme in Radiologic technology (RT), the first university master programme for radiographers in Croatia. The programme is based on the synergy of an educational path with additional knowledge from specific subfields in the area of radiologic

\footnotetext{
${ }^{3}$ available from:

https://www.sor.org/system/files/article/201402/consultant_radiographers_education_and_cpd_version2.p df
} 
technology, such as CT scanning, MRI scanning, ultrasound scanning, IT, digital radiologic systems, intervention radiology, etc.

\section{$3 \quad$ Education in Europe}

It was not until the 1960s that most European countries recognized the need for degree education for radiographers. In Sweden and in Austria, radiography as a profession started to become recognized in approximately the same period, namely around 1960 (Hillergård, 2016; Rosenblattl, 2012).

For the last thirty years the education of radiographers has moved from vocational schools into the realm of higher education following the Bologna process. The European Higher Education Area is a result of the political will of 48 countries, based on the Bologna Declaration (1999), and has as its main goal to reform the process of education and to organize a three-cycle structure. It has provided both a framework and practical tools that have modernized and improved the quality of higher education.

There are no single standards in Europe for all the countries for the formal education for radiologic technologists / radiographers. In his research, Couto concluded that the level of education varies across the EU and that there is no uniformity in the title and requirements to practice radiography (Couto et al., 2018). This effectively limits the possibility of free movement of this profession.

Study programmes of radiography with the same content and purpose in Europe last three or four years depending on the country and the higher education system. In its document "Tuning Template for Radiography and Europe" Higher Education Network for Radiography in Europe (HENRE) recommends three levels of higher education for radiologic technologists: undergraduate level (bachelor's level), graduate level (master's level) and postgraduate level (doctoral level). The proposed system of education and the conclusion on the needs and the way of harmonizing higher education for radiologic technologists in the EU is identical to the one accepted in the Croatian Model of University Education for health professionals (Janković et al., 2010). The organization of study programmes in radiography in Europe, as in most countries, is based on the guidelines of the Bologna Declaration and $3+2+3$ model of study $(180+120+180$ ECTS $)$, provided that the graduate studies are organized in the area of radiologic technology, public health and management and organization of the healthcare as well as in the areas of each study programme.

In 2011, several European universities introduced a joint study programme called the master course in medical imaging (EMPIMI) aimed at training students to adopt innovative, multidisciplinary approaches to radiologic technology, research, European guidelines to topics of legislation, cultural and social differences as well as advanced methods in radiologic technology. ${ }^{4}$

\footnotetext{
${ }^{4}$ available from: http://course.spc.at/courses/european-masters-programme-in-medical-imag-117401/
} 
University education of health professions in the majority of EU Member States is performed according to Directive 2005/36/EC. At the universities in Europe, the existing curricula of study programmes and qualification standards are based on recommendations and directives of the EU. Each country, including Croatia, structures its own study programme according to the domestic regulations and respecting the specific needs of each country.

\section{The Role of EFRS}

In the field of radiography, the qualifications required for radiographers have been changing because of the rapid progress in radiologic technology. The role of the European Federation of Radiographer Societies (EFRS) is to represent, promote and develop the profession of radiography in Europe. EFRS was founded in 2008 by 27 professional societies of radiographers. ${ }^{5}$ EFRS plays an important role in promoting and developing advanced educational standards and qualifications at both the bachelors and masters levels for education in radiography. It bridges the gap between the education and market demands. Although educational institutions should play a pivotal role in generating educated professionals, it also is important to take into account the need to satisfy job market demands according to specific needs. Since the education for radiographers in EU is organized differently and depends on the status of the radiographer profession in each country, the learning outcomes set out by EFRS should help in establishing a unified European standard for their education. The proposed benchmark for radiographers, following the descriptors of the European Qualification Framework (EQF), at level 4, 5, 6 (Bachelor), 7 (Master) and 8 (Doctoral), is in accordance with CROQF.

\subsection{European Qualifications Framework}

EQF is a common European reference framework whose purpose is to make qualifications more readable and understandable across different countries and systems in EU. The implementation of the EQF was based on the Recommendation on the European Qualifications Framework for lifelong learning adopted by the European Parliament and the Council on 23 April 2008. ${ }^{6}$

Each of the eight levels in EQF is defined by a set of descriptors indicating the learning outcomes relevant to qualifications at that level in any system of qualifications. Learning outcomes (knowledge, skills and autonomy-responsibility) express what individuals know, understand and are able to do at the end of a learning process. The level above (7th level) shows distinct progress in dimensions of change from the previous, 6th level, (e.g. complexity of knowledge) for radiographers. The learning

\footnotetext{
${ }^{5}$ In 2015 already 38 radiographer societies from 32 countries in the geographical region of Europe are registered as full member, 49 educational institutions from 25 countries joined as affiliate members and are cooperating in the EFRS educational wing. Also one trade union joined as affiliate member. EFRS represents more than 100.000 radiographers and 8000 radiography students in Europe. Available from: https://www.efrs.eu/content/content/id/122

${ }^{6}$ available from: http://www.cedefop.europa.eu/en/events-and-projects/projects/european-qualificationsframework-eqf
} 
outcomes relevant to EQF level 7 comprise, among other things, specialized problemsolving skills required in research and /or innovation in order to develop new knowledge and procedures and to integrate knowledge from different fields. ${ }^{7}$

In January 2018, the EFRS published the $2^{\text {nd }}$ edition European Qualifications Framework level 6, Benchmarking Document for radiographers ${ }^{8}$. This document presents its purposes as follows:

\section{„The purpose of the EFRS EQF level 6 benchmark document for} radiographers is to serve as a benchmark;

- informing readers about what the EFRS membership agreed to be the entrée level to the radiography profession in Europe and

- as a point of reference for use by professional bodies, educational institutions, employers, and other relevant bodies throughout Europe. “

The EFRS survey from 2017 (European Federation of Radiographer Societies, 2017) shows that for the initial qualification there is an ongoing move from vocational education to formal higher education. It is also said that the harmonization of education and the role of radiographers in Europe is a national responsibility, based not only on the content and level of education programmes, but also on the role of radiographers as defined by hospital and service policies. In this benchmark, the guidelines are clearly defined for core learning outcomes which include knowledge, skills and competences for Medical Imaging (Diagnostic Radiography), Nuclear Medicine and Radiotherapy (Radiation Therapy) for all mentioned fields of professions with personal and professional development, ethics and quality assurance. In January 2017, the EFRS published the European Qualifications Framework (EQF) Level 7 Benchmarking document for Radiographers. ${ }^{9}$ The purpose of this document is to serve as a point of reference and benchmark for educational institutions, employers and professional bodies, without intending to impose curricular content on educational institutions for the process of developing, educational programmes in radiography at $\mathrm{EQF}$ Level 7. In this document, the difference between knowledge, skills and competences for professional radiographers at the EQF level 6 and EQF level 7 is stated. Based on the foregoing, the curricula for a master degree can be categorized as Taught or Research programmes. Taught programmes may or may not include a research thesis, depending on particular institutional or national regulations. Independent, supervised research in a particular field of study is essential for Research Master programmes. Working with students under the supervision of a supervisory team at the Master level is based on original thinking and /or research. Some important

\footnotetext{
${ }^{7}$ available from: https://ec.europa.eu/ploteus/sites/eac-eqf/files/brochexp_en.pdf

${ }^{8}$ available from:

https://www.efrs.eu/publications/see/EFRS_EQF_level_6_benchmark_document_for_radiographers._Sec ond edition - February 2018?file $=1261$

${ }^{9}$ available from:

https://www.efrs.eu/publications/see/2016.11_EFRS_EQF_level_7_Benchmark_(Master)?file=1083
} 
components of a Master programme for radiographers /radiologic technologists are clinical audit, communication, devices and technology, evidence-based practice, leadership and management, patient safety (including patients' rights and legislation on patients' safety), radiation protection, reflection, research, risk management, quality control / assurance (EFRS, EQF level 7, 2017).

\section{The Role of ESCO}

There are problems across Europe both in understanding qualifications and in the lack of an easy way to compare them. In order to solve these problems, the European Commission founded ESCO. ${ }^{10}$ ESCO is a multilingual classification of European skills, competences, qualifications and occupations. The mission of ESCO is connecting the education and training institutions with labour market actors by making skills, competences and qualifications visible and comparable at the EU level of EQF. International Standard Classification of Occupations (ISCO) ${ }^{11}$ is a four-level classification of occupation groups managed by the International Labour Organisation (ILO). Its structure follows a grouping by education level. ESCO helps in providingsupport in communication between the world of work and the world of education and training. According to its vision, using the multilingual classification of European skills, competences, qualifications and occupations, will help all the actors in the European labour market, and in the education and training systems, to develop a shared understanding of occupations, skills, competences and qualifications. It connects different countries in order to help the domains of employment, education and training, by providing a complete picture of the labour market and education-related information. ESCO explains to employers the learning outcomes of people in practice (the knowledge, skills and competences they obtained in education), and which knowledge, skills, competences ${ }^{12}$ and qualifications they expect from their employees in order to find the right person for a job. For individuals, ESCO could be helpful in developing their career through lifelong learning and continuing professional development (CPD); it describes their knowledge, skills and competences in order to find the right job.

In the field of education, it helps learning institutions to express their learning outcomes in a way that not only facilitates the understanding of their qualifications across borders but also attracts learners from across borders. The description of radiographers according to $\mathrm{ESCO}$ is:

"Radiographers use a range of technologies to examine, treat and care for patients. They work in the fields of Medical Imaging, Radiotherapy and Nuclear Medicine and apply ionising radiation, ultrasound, magnetic resonance imaging and radioactive sources."

\footnotetext{
${ }^{10}$ available at: https://ec.europa.eu/esco/portal/home

${ }^{11}$ available from:

http://www.ilo.org/wcmsp5/groups/public/@dgreports/@dcomm/@publ/documents/publication/wcms_17 2572.pdf

${ }^{12}$ The list of Essential skills and competences and essential and optional knowledge is made by ESCO, available from: https://ec.europa.eu/esco/portal/occupation
} 
Significant progress for radiographers was made in November 2017 when ESCO confirmed the upgrade of the Radiographer profession by linking it to the ISCO-08 Major Group 2 "Professionals" instead of ISCO Major Group 3 "Technicians and Associate Professionals". Therefore, radiographers should be provided with both theoretical and practical training for their occupations for which a higher qualification is required. The enormous difference in the educational qualifications of radiographers previously inhibited the free movement of labor within the EU. Ministers responsible for Higher Education and the heads of delegation, institutions and organizations participating in the 5th Bologna Policy Forum, strongly support the continuing value that higher education brings to societies. They point out:

“...the Bologna Policy Forum, supported by Ministers and international organisations, can bring about a more systematic and sustainable level of international cooperation. This cooperation needs to take account of diversity across our regions, including the different domestic social and political contexts of higher education and its wider geopolitical dimension. It should define realistic ambitions and goals that can be achieved in a spirit of exchange and mutual learning. It is important for those with responsibility for higher education to listen, learn and engage on common issues". ${ }^{13}$

At that Forum, Ministers adopted the revised overarching framework for qualifications. It comprises the short cycle, the first cycle, the second cycle and the third cycle generic descriptors for each cycle based on learning outcomes and competences, and credit ranges in the short cycle, first and second cycles. Ministers committed themselves to elaborating national frameworks for qualifications compatible with the overarching framework for qualifications in the European Higher Education Area (EHEA).

Most Member States, as well as Croatia, have been developing their own National Qualifications Framework (NQF), which help to make qualifications easier to understand and compare, classifying them by level, based on learning outcomes. EQF links countries' qualification system and helps to understand the qualifications in different countries. The content and profile of qualifications are understandable: what the holder of a certificate or diploma is expected to know, understand, and be able to do. All of this will help people to move more easily between education and training institutions and sectors. Accordingly, EQF promotes mobility, lifelong learning and continuing professional development.

\footnotetext{
${ }^{13}$ Statement of the Fifth Bologna Policy Forum, available from: http://www.ehea.info/media.ehea.info/file/2018_Paris/36/8/BPFStatement_with_Annex_958368.pdf
} 
High education of health care workers in Croatia is implemented in a well-organized network of faculties. The formal education of radiographers in Croatia is regulated by law, namely the Act on Scientific Activity and Higher Education. ${ }^{14}$ It is based on two levels, a two cycle higher education system, as professional and university study level (Janković et al., 2010). There is the possibility of attending and completing doctoral studies in the field of biomedicine and health or other interdisciplinary field. University studies consist of academic programmes that are conducted solely at universities, while professional studies consist of professional programmes conducted at polytechnics or colleges of applied sciences. Exceptionally, according to the mentioned Act, professional programmes can also be implemented at universities.

Education for Radiologic Technologist / Radiographers

In Croatia, as well as in other Member States of the EU, healthcare professions are regulated by law. They have to be registered, licensed and relicensed by their respective professional chamber. Eight categories of the medical profession are regulated by medical chambers in Croatia: medical doctors; dentists; pharmacists; nurses; midwives; medical biochemists; physical therapists; and other health care professionals (sanitary monitoring staff, radiology technical staff, occupational therapists, medical laboratory staff). Radiographers are health professionals who operate advanced equipment who must constantly adapt to fast-moving technological skills through, for example, lifelong learning processes, workshops, etc. This ongoing training is necessary, among other reasons, because they bear the responsibility for the procedures they perform. They are charged with making sure that the results of their examinations are accurate and therefore are responsible for ensuring they take functional images that will help doctors to make their diagnoses. Inadequate images prolong the waiting time for a patient who is waiting for the clarification in connection with his illness. According to the several studies (Bro Brask \& Birkelund, 2014), patients link the quality of care with the information provided while awaiting results of the examination. That technological environment and radiologic equipment may be very stressful for patients, so they may change their decisions.

The role of legal medicine is very important today and it has been growing in significance. Today we need to talk about patient's rights and responsibilities in order to protect both the health workers themselves and that of the patients. Nowadays, for interventional procedures written informed consent has become the standard practice, but in the field of diagnostic radiology informed consent has not developed at the same rate. The relationship between patients and health workers depend on trust and by giving consent, the patient is involved in the process of decision-making and agrees with the outcome. Consent has become a legal requirement for medical procedure and care.

\footnotetext{
${ }^{14}$ Act on Scientific Activity and Higher Education (Official Gazette, 123/03, 198/03, 105/04 , 174/04, 02/07, 46/07, 45/09, 63/11, 94/13, 139/13, 101/14, 60/15, 131/17).
} 
This applies to radiologic technologists / radiographers, whose education must meet the minimum conditions as provided in Directive 2005/36/EZ. Undergraduate and graduate study programmes in Radiologic Technology ${ }^{15}$ are based on defined outcomes at the sixth and seventh level of education, and must be compatible with similar programmes in the EU, which thereby helps to ensure the mobility of both students and teachers. The courses are delivered in modules with specific goals to acquire knowledge, skills and competences which are necessary, so that the outcomes meet the requirements for the education of radiographers / radiologic technologists, according to EQF.

Education at the Bachelor level lasts for at least three academic years, comprising 4,600 hours of teaching and study, which corresponds to 180 ECTS credits. According to the Directive, more than $51 \%$ of the practical teaching hours take place through aclinical teaching setting. In that way, students are in direct contact with patients, under the supervision of their mentors. The University Department of Health Studies, University of Split performs two levels for radiologic technologist / radiographers, according to the 3+2 model for bachelor and master degrees: an undergraduate study programme (bachelor, BS) and a graduate study programme (master, MS). Enrolment requirements for the Master study at this University in Croatia are: completed undergraduate university study programme in Radiologic technology (180 ECTS credits) with a grade average score of at least 4,0, or at least 3,0 with written references of three university professors, and at least one year of professional work in the health system. Education at the master level lasts for at least two academic years comprising approximately 3,000 hours of teaching and study, which corresponds to 120 ECTS credits.

Professionals educated in this way will be able to responsibly participate in the education of radiologic technologists at the undergraduate university level. The student is awarded the title of Bachelor degree in Radiologic technology, after passing all the exams and defending the final thesis, according to the Act on Science and Higher Education and Act on Academic and Professional Titles and Academic Degree. ${ }^{16}$ The student then obtains the state authorization for independent work in the health care system in Croatia.

At the Master level, the student should develop competences in analyzing, synthesizing and applying knowledge through formal courses, seminars, clinical training, hospital practice and mentorship as well as acquire skills of lifelong independent learning. The courses from the field of Radiologic technology are structured and based on principles and techniques of evidence-based medicine and evidence-based practice. The learning outcomes are clearly defined and the course content is completely covered by teaching lessons.

\footnotetext{
${ }^{15} \mathrm{We}$ analyzed study programmes for radiologic technology at the University of Split, Department for Health Studies, $6^{\text {th }}$ and $7^{\text {th }}$ level.

${ }^{16}$ Act on Academic and Professional Titles and Academic Degree (Official Gazette, 107/07, 118/12).
} 
It is important to emphasize that the education of health professionals at the University of Split is unique in that the curricula provides for common courses for five health professions ${ }^{17}$ in the first year of study. Following the curricula in the European Union based on the Croatian Model of University Education for health professionals, the introduction of modules with common courses at the first year of undergraduate and graduate study programmes makes the organization of this study programmes specific to this region. The advantages of implementing study programmes in this manner can be seen in cost reduction, increased mobility of students and teachers, improved quality of teaching and developing teamwork (University of Split, University Department of Health Studies, Self-evaluation, 2015).

\section{The Importance of Developing Profession and Education of RT}

The health care system is primarily governed by the Health Care Act. ${ }^{18}$ According to this Act, Croatia fulfills its rights, responsibilities and goals in the field of healthcare by ensuring the conditions for education of health workers (Health Care Act, article 5). Radiologic technologists, also known as radiographers, are registered health professionals under the Act on Health Professions, Official Gazette of the Republic of Croatia (Official Gazette, 87/09).

The science, as well as the professional work of radiography and the radiographers, has been rapidly developing over the years. The development of radiologic devices and technology leads to the constant improvement of both teaching methods and learning outcomes and competences in the learning process of providers of radiography education (EQF 6). Bjørnstad (2018) observes that the role of the radiographer has changed, due to continual developments in technology, and it can be concluded that there is a need for restructuring of radiography education in order to reevaluate the learning outcomes. The employers should participate in this process, because the required competences of a clinical diagnostic radiographer are both ongoing and a dynamic process. Studies have shown that due to the dynamic nature of the profession, there is a contiuous need for an increase in competencies for radiographers beyond the Bachelor degree. Additionally, Hammerstrøm suggested that a further focus on evidence-based practice is needed for developing guidelines and protocols in imaging departments in Norway. In his study, it is also observed that the radiographers who had little knowledge about use of evidence-based practice in imaging diagnostics held the perception that the method is unnecessary and complicated. Contrary to that, those radiographers who had training courses in evidence-based practice believed that the method is suitable (Hammerstrøm, 2017).

Using novel teaching methods and technology enables dissemination of knowledge and helps students to coordinate their working obligations with studying. Higher education institutions are forced to adapt new trends in delivering education (Ros, 2016). The flipped classroom is a face-to-face interaction, mixed with independent

17 Five health professions are: radiologic technology, nursing, midwifery, medical laboratory, physiotherapy.

${ }^{18}$ Health Care Act (Official Gazette, 150/08, 71/10, 139/10, 22/11, 84/11, 154/11, 12/12, 35/12, 70/12, $144 / 12,82 / 13,159 / 13,22 / 14,154 / 14,70 / 16,131 / 17$. 
study via technology that allows students to study course material at home while inclass time is dedicated to homework and assignments. This method helps students who are dividing their time between school, work, family and other interests. The passive approach to students has been rejected, in order to make a movement toward interactive teaching, for example "journal club". Journal club is a method of active learning in medical education, focused on critical thinking. It incorporates basic principles of active and adult learning. It also advances students' scientific skills beyond basic knowledge and comprehension. Students have an opportunity to develop critical thinking, communication skills, and personal confidence in these skills (Rosenthal \& Rosenthal, 2017).

The adaptation and implementation of highly sophisticated devices improves medicine and patient care but correlatively also increases the responsibility of radiographers. Girard concludes that the emergence of new technologies is putting pressure on radiographers who need to be helped and brought to the highest possible level of education (Girard, 2012). Society should help this profession and encourage radiographers, especially by offering them participation to congresses and continuous education through CPD and / or lifelong learning.

The knowledge improvement can be made by teaching and researching, since all higher education must rest on a scientific basis (Fridell, 2016). Implementation of a research process leads to the quality improvement and the radiography programmes already include research process and evidence based methods of thinking in both Sweden and in Croatia. (University of Split, School of Medicine, 2010; Costa [et al], 2017).

In accordance with previous findings, McNulty reports about the importance of research and evidence-based practice and the contribution of radiographers in these activities (McNulty, 2018). He points out the role of EFRS and Benchmarking document for Radiographers (EQF) level 6 and 7 in supporting and developing a highquality radiographer role, because they can add value at all stages of the research process for medical imaging research.

Conceição in his survey suggests positive attitudes towards research among radiographers and concludes thatresearch related courses are needed in order to increase students' involvement in research activities (Conceição et al., 2018).

The Swedish experience shows that the integration of a radiographer in a preclinical imaging department presents an added value to scientific projects and leads toward new opportunities for radiographers in the future. Without the master and $\mathrm{PhD}$ education the radiographer has a lack of adequate knowledge of research (Dillenseger, 2018). 
These findings are similar to those of other studies, which concluded that radiographers had pivotal and developing roles with the advent of new technologies (Butler, 2012). The importance of education and training in the development of the role of the radiographer in quality assurance and radiation protection, improve and raise the quality in diagnostic procedures and exams.

\subsection{Postgraduate Education}

Technology has changed the world of radiography significantly in just the past decade. The rapid expansion of technology has also had a dramatic effect on the personal and professional lives of radiographers. Today, the development of education in radiography / radiologic technology is very important not only for the students but also for the teachers who work in the field of radiography education. Most experts and several studies exploring education in the field of radiography agree that improvements are necessary and should focus on the harmonization of the process of education for radiographers in Europe; following technological developments; and; meeting job market demands. The EU and its various bodies aim to develop the harmonization of education and free movement of professionals in Europe, while at the same time respecting the specific needs of each country. There is a room for upgrading in educational strategies in radiography, as an interdisciplinary area with dual knowledge from natural sciences and the humanities, which will influence demands from the job market (Sá dos Reis et al., 2018). There have been several studies performed that have explored the competences and skills for radiographers and they uniformly conclude that there are differences in current educational requirements across the EU (Prentakis et al., 2016). This lack of uniformity in educational requirements has led to problems, including the free movement of radiologists across EU Member States. The conclusion of Prentakis' study is that the establishment of a radiographers' degree at the university level is expected to improve the quality of the services. The study strongly supports active involvement of radiographers in adoption of CPD system to acquire new knowledge, to develop new skills and assure provision of high quality of service (Prentakis et al., 2016).

It is significant to note that presently there is an insufficient number of teaching staff members holding master's and doctoral degrees. Radiography, as a profession, can make meaningful strides forward after providing the conditions for further education for the teaching staff, including the support for taking on doctoral degrees and conducting research (Sá dos Reis et al., 2018). Unfortunately, today there is a shortage of radiographers holding Master's degrees and postgraduate diplomas in most European countries. Today in Croatia there is only one radiographer holding a doctoral degree. Andersson has reported that in Sweden there are 20 radiographers holding PhD's (Andersson, 2016), even though it has been recognized as a profession since the 1960s. The reason for this relatively small number is because the number of educational institutions offering $\mathrm{PhD}$ 's is limited. 
Björkman explored the trends that have the potential to predict the future for the radiography profession in Sweden in 2025 and highlighted that radiographers need postgraduate education (Björkman et al., 2017). Their study has clearly shown that radiographers need more advanced knowledge and skills in order to take greater responsibility for diagnostic procedures and thus to enhance overall patient care. In the future radiographers will take on what is known as "role extension", which will require them to have advanced skills and knowledge, which only further training and education will qualify them for. By "role extension" we mean that they will be taking on tasks that were previously the sole responsibility of radiologists, for example image post processing.

Additionally, inter-professional collaboration is very important. Therefore, it is critical that both educational and workplace institutions work together in a collaborative fashion, as this will promote a sort of synergy, and all EU Member States should actively encourage and promote this. We think that inter-professional education (IPE) programs will be expanding, as they are increasingly viewed as a means of reducing medical errors and improving the health care system. At the University of Split, inter-professional education is a component of the curricula at both the bachelor's and master's levels for all health workers. Through their postgraduate education, radiographers will be better prepared to take on new professional challenges and responsibilities. It is therefore critically important not only that educational opportunities in radiography must be expanded at high educational institutions, but also that research in the profession take on a higher level of importance. In 2016, one study revealed that almost one-third of educational institutions in Europe did not provide any post-doctoral program for radiographers. Given the importance of education this is not acceptable and probably helps to explain stagnation in the profession (Björkman et al., 2017).

In their research, Gonzaga Mubuuke and Pope (Gonzaga Mubuuke and Pope, 2015) have demonstrated that various factors, both intrinsic and extrinsic, are likely to influence radiographers' decision to pursue postgraduate education. The intrinsic factors are: the desire for personal professional development, the desire for new challenges and the search for professional satisfaction. The availability of funding, availability of postgraduate programs and changes within the profession are observed as extrinsic factors that influenced radiographers to pursue postgraduate education. The results have shown that radiographers have the desire for personal development and that they hope to acquire more advanced skills and knowledge through postgraduate education in order to advance themselves professionally, and also to improve clinical practice and patient care. The overall conclusion of the research of teaching qualifications of radiography lecturers and teachers across Europe in 2010 was the importance of the need for radiographers to obtain further education beyond the bachelor's level, such as MSc or PhD as well as teaching qualifications (Davis, 2010). 
In accordance with these previous findings, it should be highlighted that government support is needed so the students can better afford their postgraduate education (Gonzaga Mubuuke and Pope, 2015). Obtaining postgraduate degrees will help enable radiographers to take on greater leadership roles within their departments and will allow them to better participate in the decision-making process. For all of the reasons previously stated in this article, it has become obvious that the development of radiologic technologies and the radiologic science has created both the opportunities and needs for the introduction of the radiologic technology study program at the postgraduate level. The appropriate measures, such as planning and delivering new programs at graduate level to raise and maintain standards of education should be taken in each country because of the shortage of qualified teachers and it is important to focus on educational achievement for both teachers and students. As mentioned above, in Croatia there is only one radiographer holding a doctoral degree and in Sweden there are 20 radiographers holding PhD's (Andersson, 2016). Our findings regarding the need for radiography educators obtaining postgraduate education correlate with the results of the survey by McNulty et al. (2015) of the need for radiography educators to progress to Masters and Doctoral status (McNulty et al., 2015). The conclusion of McNulty's study was that the level of postgraduate education opportunities for radiographers across Europe was insufficient and required support, It is important to develop postgraduate programmes which include the critical thinking and research standards for radiographers.

Regarding the development of the radiography profession, the further need for research, continuous professional development and application of clinical thinking will continue to grow. The conclusion of one study (Sá dos Reis et al., 2018) is to consider the specific requirements of each country and then to identify common strategies to harmonize radiography in Europe. The common strategy should be the improvement of knowledge, critical thinking and research as well as to support practice based on evidence, and we all agree with that. The importance of clinical placement as a core component of radiography education has been revealed in the first European survey of clinical radiography education (England et al., 2017). The findings in the survey suggest that EFRS should consider methods to further harmonize the provisions on clinical education. It has been concluded that the institutions need support in process of planning and delivering new programmes.

\section{Conclusion}

This article has clearly shown that the development of radiography / radiologic technology and the radiologic science has created opportunities and needs for the new approach to the radiographer's profession and introduction of the radiologic technology study program at both the graduate and postgraduate levels. In order to ensure enhancement and further positive development of the radiographer's profession, society should provide the right conditions for further education for both the teaching staff and practitioners, including the support for both post-graduate study and research. 
Additionally, harmonization and development of the radiographer's profession following technological development considers cooperation among educational institutions, employers and professional bodies, within the framework of European and national legislation.

Being professionally motivated for their own growth in order to provide high-quality healthcare services, radiographers will gain the power, which will move the science of radiography and researches to radiographers. Obtaining master's or doctoral degrees will enhance the opportunities for radiographers to assume leadership roles within their departments so they can better actively participate in the decision-making process.

This article has revealed that the radiographer's profession, if upgraded with knowledge and learning outcomes relevant to qualifications at level 7 (master) and 8 (doctoral), will be much better equipped to face future challenges and opportunities.

\section{Legal sources:}

Act on Academic and Professional Titles and Academic Degree (Official Gazette, 107/07, 118/12).

Act on Croatian Qualification Framework (Official Gazette, 22/13, 41/16, 64/18).

Act on Health Professions, Official Gazette of the Republic of Croatia (Official Gazette 87/09).

Act on Scientific Activity and Higher Education (Official Gazette, 123/03, 198/03, 105/04, 174/04, 02/07, 46/07, 45/09, 63/11, 94/13, 139/13, 101/14, 60/15, 131/17).

Croatia Qualifications Framework, Government of the Republic of Croatia (2009).

Directive 2005/36/EC of 7 September 2005 on the recognition of professional qualifications.

Health Care Act (Official Gazette, 150/08, 71/10, 139/10, 22/11, 84/11, 154/11, 12/12, 35/12, $70 / 12,144 / 12,82 / 13,159 / 13,22 / 14,154 / 14,70 / 16,131 / 17)$.

The Bologna Declaration of 19 June 1999. Joint Declaration of the European Ministers of Education.

The European Qualifications Framework for lifelong learning (EQF) (2008) European Commission Luxembourg.

\section{References}

Andersson, B. T. (2016) The Swedish radiographer as a professional, Postgraduate Educational Programme. Insights Imaging, 7(Suppl 1), pp. 1-161, published online (Feb 12, 2016), doi: 10.1007/s13244-016-0474-9.

Björkman, B., Fridell, K. \& Tavakol Olofsson, P. (2017) Plausible scenarios for the radiography profession in Sweden in 2025, Radiography, 23(4), pp. 314-320, doi: 10.1016/j.radi.2017.07.002.

Bjørnstad A. (2018) Education vs clinical practice, Postgraduate Educational Program. Insights Imaging, 9(Suppl 1), pp. 1-642, published online (Feb 15, 2018), doi: 10.1007/s13244-018-0603-8.

Bro Brask, K. \& Birkelund, R. (2014) "Patient Care in Radiology"- The Staff's Perspective, Journal of Radiology Nursing, 33(1), pp. 23-29, doi: 10.1016/j.jradnu.2013.12.001.

Conceição, I., Abrantes, A. F., Ribeiro, L. P, Rodrigues, S. I. \& Almeida, R. P. (2018) A survey on the attitude towards research among radiographers, Postgraduate Educational Program. Insights Imaging, 9(Suppl 1), pp. 1-642, published online (February 15, 2018), doi: 10.1007/s13244-018-0603-8. 
Consultant Radiographers Education and CPD (2013), retrieved from:

https://www.sor.org/system/files/article/201402/consultant radiographers_education and cpd version2.pdf (April 10, 2019)

Costa, C., Abrantes A. F., Ribeiro L. P., Azevedo, K. B., Almeida R. P. P., Lesyuk O. \& Silva, C. A. (2017) Evidence-based practice in radiology: the radiographer perspective, European Society of Radiology, doi: 10.1594/ecr2017/B-0823.

Couto, J.G., Hughes, C., McFadden, S., McClure, P. \& Bezzina, P. (2018) An evaluation of the educational requirements to practice radiography in the European Union, Postgraduate Educational Program, Insights Imaging, 9(Suppl 1), pp. 1-642, published online (Feb 15, 2018), doi: 10.1007/s13244-018-0603-8.

Davis, M.D.J. (2010) To explore teaching qualifications of radiography lecturers and teachers across Europe, Insights Imaging, 1(Suppl 1), pp. 127-322, published online (Mar 9, 2010), doi: 10.1007/s13244-010-0011-1.

Dillenseger, J.-P. (2018) Radiographers in preclinical research: challenges and chances, Postgraduate Educational Program, Insights Imaging, 9(Suppl 1), pp. 1-642, published online (Feb 15, 2018), doi: 10.1007/s13244-018-0603-8.

England, A., Geers-van Gemeren, S., Henner, A., Kukkes, T., Pronk-Larive, D., Rainford, L. \& McNulty J.P. (2017) Clinical radiography education across Europe, Radiography, 23(Suppl 1), pp. S7-S15, doi: 10.1016/j.radi.2017.05.011.

European Federation of Radiographer Societies (2017) European Qualifications Framework (EQF) Level 7 Benchmarking document: Radiographers (Utrecht, the Netherlands: European Federation of Radiographer Societies).

Fridell, K. (2016) Implementation of a research process and quality improvement within the Swedish radiography program, Postgraduate Educational Program. Insights Imaging, 7(Suppl 1), pp. 1-161, published online (Feb 12, 2016), doi: 10.1007/s13244-0160474-9.

Girard, F. (2012) The impact of radiographers on performance and quality issues arising with novel technology, Postgraduate Educational Program. European Congress of Radiology 2012. Insights Imaging, 3(Suppl 1), pp. 1-134, published online (Mar 21, 2012), doi: 10.1007/s13244-012-0153-4.

Gonzaga Mubuuke, A. \& Pope, E. (2015) Factors that Influence Radiographers' Decision to Pursue Postgraduate Education: An Exploratory Qualitative Study, Journal of Medical Imaging and Radiation Sciences, 46(2), pp. 223-230, doi: 10.1016/j.jmir.2014.11.002.

Hammerstrøm, L. (2017) Do radiographers find evidence-based practice (EBP) a suitable tool for developing guidelines or protocols in imaging departments? Postgraduate Educational Program. Insights Imaging, 8(Suppl 1): 1-583, published online (Feb 16, 2017), doi: 10.1007/s13244-017-0546-5.

Hillergård K. (2016) Introduction (part 2) to EM 4, The professional role of Swedish radiographers in medical imaging, Postgraduate Educational Program, Insights Imaging, 7(Suppl 1), pp. 1-161, published online (Feb 12, 2016), doi: 10.1007/s13244016-0474-9.

Janković, S., Mihanović, F. \& Šimunović, V. (2010) The Croatian Model of University Education for Health Professionals, Collegium Antropologicum, 34(4), pp. 1481-1485.

McNulty, J. (2018) An overview of the roles of radiographers in research, Postgraduate Educational Program. Insights Imaging, 9(Suppl 1), pp. 1-642, published online (Feb 15, 2018), doi: 10.1007/s13244-018-0603-8.

McNulty J. P., et al., (2015) A picture of radiography education across Europe, Radiography, 22(1), pp. 5-11, doi: 10.1016/j.radi.2015.09.007.

Prentakis, A. G., Stefanoyiannis, A. P., Georgiadis, K., Coleman, L., Foley, S. J., Herlig, D., Kollas, P., Kowalik, A., Tomczak, J. \& Chatziioannou, S. N. (2016) Education, training, and professional issues of radiographers in six European countries: a 
comparative review, Journal of European CME, 5(1):31092, doi: 10.3402/jecme.v5.31092.

Ros, P. (2016) Role of remodeling in delivering of learning, Postgraduate Educational Program, Insights Imaging, 7(Suppl 1), pp. 1-161, published online (Feb 12, 2016), doi: 10.1007/s13244-016-0474-9.

Rosenblattl, M. (2012) The change from diploma to bachelor's degree: new perspectives for students and staff, Postgraduate Educational Program, European Congress of Radiology 2012, Insights Imaging, 3(Suppl 1), pp. 1-134, published online (Mar 21, 2012), doi: 10.1007/s13244-012-0153-4.

Rosenthal, J. \& Rosenthal, K. S. (2017) Interactive Journal Club: Teaching an Old Dog New Tricks, Journal of Medical Education and Curricular Development, 4, pp. 1-6, doi: 10.1177/2382120517719710.

Sá dos Reis, C., Pires Jorge, J.A., York, H., Flaction, L., Johansen, S. \& Mæhle, S. (2018) A comparative study about motivations, expectations and future plans for professional development in four European radiography programs, Radiography, 24(4), pp. e91-97, doi: 10.1016/j.radi.2018.05.007.

Tuning Template for Radiography and Europe, retrieved from: http://www.unideusto.org/tuningeu/images/stories/Summary_of_outcomes_TN/Tunin g_template_for_Radiography_in_Europe.pdf (April 10, 2019)

University of Split, School of Medicine (2010) Elaborate justification of the founding of the Faculty of Health Studies (University of Split).

University of Split, University Department of Health Studies (2015) Self-evaluation, 2015. 